\title{
Investigation of Disordering in Natural Arsenopirite by X-Ray Powder Crystal Structure Analysis and Nuclea Gamma Resonance
}

\author{
Sergey D. Kirik*a, Anatoly M. Sazonov ${ }^{\text {a }}$, \\ Sergey A. Sil'yanov a and Oleg A. Bayukov ${ }^{\mathrm{b}}$ \\ ${ }^{a}$ Siberian Federal University \\ 79 Svobodny, Krasnoyarsk, 660041, Russia \\ ${ }^{b}$ L.V. Kirensky Institute of Physics SB RAS \\ 50/38 Akademgorodok, Krasnoyarsk, 660036, Russia
}

Received 12.03.2017, received in revised form 17.04.2017, accepted 21.05.2017

The features of the FeAsS arsenopyrite crystal structure disordering occurred in geological conditions were studied by elemental analysis, X-ray diffraction and Mossbauer techniques using natural samples. There were selected and studied three practically single-phase polycrystalline samples of Blagodatnoe and Olimpiada ore deposits (Krasnoyarsk region) with the chemical composition close to stoichiometry (I), with excess sulfur (II) and arsenic (III).

The Mossbauer (NGR) study detected the presence of the three forms of $\mathrm{Fe}(2+)$ in the substance. The first was associated with octahedral iron environment of $\left[\mathrm{As}_{3} \mathrm{~S}_{3}\right]$ type, the second with $\left[\mathrm{S}_{6}\right]$ and third with $\left[\mathrm{As}_{6}\right]$ forms conventionally associated with ordered arsenopyrite and $\mathrm{FeS}_{2}, \mathrm{FeAs} \mathrm{s}_{2}$ minerals. According to NGR data the iron atoms at $95 \%$ were in the main form in the sample (I). Other forms were present about in equal parts. There were detected $73 \%$ and $56 \%$ of iron in its basic form for samples (II) and (III) respectively with $\mathrm{FeS}_{2}, \mathrm{FeAs} \mathrm{s}_{2}$ dominated as by-forms.

$X$-ray powder crystal structure refinement was carried out in Space group $P 2_{1} / c$. It was established that the iron atoms were in cationic positions of the arsenopyrite. Additional crystallographic positions of iron were not detected. The structure variation mainly occurred in the anion sublattice disordering the primary iron coordination from $\left[\mathrm{FeAs}_{3} S_{3}\right]$ to the condition described as $\left[\mathrm{Fe}\left(A s_{3-x} S_{y}\right)\left(S_{3-y} A s_{y}\right)\right]$. It was established that the mutual substitution of anions was accompanied by a small shift of the atomic positions due to the difference in the interatomic distances of $\mathrm{Fe}-\mathrm{S}$ and $\mathrm{Fe}$-As. Disordered condition admits the predominance of one of the anions. As a result, there are the set of the iron atom states with different composition and spatial configuration of the substituents in the coordination sphere in the real crystal. The disordering coordination of iron atoms obtained from X-ray diffracted data quantitatively corresponds to the data of NGR spectroscopy.

Keywords: arsenopyrite, crystal structure, disordering, X-ray diffraction analysis, Mossbauer spectroscopy.

Citation: Kirik S.D., Sazonov A.M., Sil'yanov S.A., Bayukov O.A. Investigation of disordering in natural arsenopirite by x-ray powder crystal structure analysis and nuclea gamma resonance, J. Sib. Fed. Univ. Eng. technol., 2017, 10(5), 578-592. DOI: 10.17516/1999-494X-2017-10-5-578-592.

(c) Siberian Federal University. All rights reserved

* Corresponding author E-mail address: kirik@icct.ru 


\title{
Исследование разупорядочения
}

\section{в структуре природного арсенопирита \\ рентгеноструктурным анализом поликристаллов}

\section{и ядерным гамма-резонансом}

\author{
С.Д. Кирик ${ }^{\mathrm{a}}$, А.М. Сазонов ${ }^{\mathrm{a}}$, \\ С.А. Сильянов ${ }^{a}$, О.А. Баюков ${ }^{\sigma}$ \\ ${ }^{a}$ Сибирский федеральньий университет \\ Россия, 660041, Красноярск, пр. Свободный, 79 \\ ${ }^{6}$ Институт физики имени Л.В. Киренского СО РАН \\ Россия, 660036, Красноярск, Академгородок, 50/38
}

\begin{abstract}
Для выявления особенностей разупорядочения кристаллической структуры в геологических условиях проведено сравнительное рентгеноспектральное, рентгеноструктурное и мессбауэровское исследование природных образцов арсенопирита FeAsS. Для исследования отобрано три практически однофазных поликристаллических образиа из руд месторождений «Благодатное» $и$ «Олимпиада» (Красноярский край) с химическим составом близким к стехиометрическому (I), с избытком серы (II) и мышьяка (III). Расшифровка мессбауэровских спектров обнаружсила наличие в веществе трех форм $\mathrm{Fe}(2+)$. Первая ассоииирована с

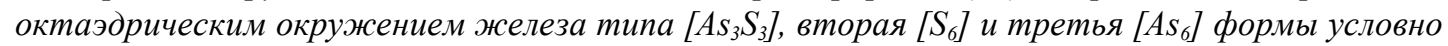
связаны с минералами $\mathrm{FeS}_{2}$ и $\mathrm{FeAs}$. Согласно данным ЯГР в образце (I) атомы железа на $95 \%$ находятся в основной форме. Другие формы присутствуют в примерно равных долях. В образиах (II) и (III) обнаружено 73 и 56 \% железа в основной форме, в качестве побочных форм преобладают $\mathrm{FeS}_{2}$ или $\mathrm{FeAs}_{2}$ соответственно. Уточнение кристаллической структуры по рентгеновским поликристаллическим данным проведено в Пр.гр. P2//с. Атомы железа размещзаются в единственной катионной позиции структуры арсенопирита. Структурные изменения происходят в анионной подрешетке путем разупорядочения основного координационного окружения железа $\left[\mathrm{FeAs}_{3} \mathrm{~S}_{3}\right]$ до состояния, описываемого как $\left[\mathrm{Fe}\left(\mathrm{As} \mathrm{s}_{3-x} \mathrm{~S}_{x}\right)\right.$ $\left.\left(S_{3-y} A s_{y}\right)\right]$. Установлено, что взаимное замещение анионов сопровождается небольшим сдвигом атомной позиции из-за разницы межатомных состояний $\mathrm{Fe}-\mathrm{S}$ и $\mathrm{Fe}$-As. Разупорядоченное состояние допускает преобладание одного из анионов. В результате в реальном кристалле образуетсянабор состоянийатомажелеза, различающихся посоставукоординационнойсферы и по пространственной конфигурации заместителей в ней. Разупорядочение координационного окружения количественно соответствует данным ЯГР-спектроскопии.
\end{abstract}

Ключевые слова: арсенопирит, кристаллическая структура, разупорядочение, рентгеноструктурный анализ, месбауэровская спектроскопия.

Арсенопирит относится к минералам гидротермального происхождения и является одним из наиболее распространенных минералов мышьяка в эндогенных месторождениях золота. Несмотря на важность для месторождений золота, а также как фактора отрицательного влияния арсенопирита на «загрязнение» руд мышьяком, кристаллохимические исследования арсенопирита относительно ограничены. Малочисленность структурных данных контрастирует с большим объемом химических данных, что свидетельствует о разнообразии составов арсенопирита. Согласно экспериментальными исследованиями Кретшмара и Скотта [1] общая формула арсенопирита может быть записана как $(\mathrm{Fe}, \mathrm{Co}, \mathrm{Ni})(\mathrm{As}, \mathrm{Sb})_{1+x}(\mathrm{~S}, \mathrm{Se})_{1-\mathrm{x}}$. В соотношении As:S может 
наблюдаться сильная нестехиометрия, при этом х варьируется не менее чем в интервале от 0.05 до -0.14 [2].

После первого структурного определения, выполненного Бюргером еще в 1936 г. [3], детальное кристаллохимическое исследование обогащенного серой арсенопирита из Фрайберга (Германия) проведено в 1961 г. Моримото и Кларком [4]. В данной работе был учтен химический состав, нестехиометрия, структурные данные и двойникование арсенопирита. Фуэсс с соавторами [5] изучали пробу обогащенного серой арсенопирита из Хакансбода (Швеция), в которой также было отмечено высокое содержание кобальта. В.В. Мурзин с соавторами [6] выполнил мессбауэровское спектроскопическое исследование (ЯГР) на ядрах ${ }^{57} \mathrm{Fe}$ на пробах арсенопирита из двух различных месторождений золота. ЯГР-спектроскопия дала неожиданные результаты, указывающие на сосуществование нескольких неэквивалентных позиций атомов железа.

Для выяснения ситуации с наличием дополнительных позиций железа недавно группой французских исследователей [7] был проведен тщательный анализ кристаллической структуры однородной пробы арсенопирита с составом, близким к стехиометрическому FeAsS, из карьера Ля-Роше-Балуэ (Франция). По монокристальному образцу весом менее 1 мг авторы подтвердили кристаллографические данные по структуре арсенопирита с единственной позицией для атома железа [3-5]. Параллельно на поликристаллической пробе весом около 40 мг было выполнено ЯГР-исследование, которое указало на присутствие трех неэквивалентных позиций атомов железа, как и в работе [6]. По результатам сделан вывод о необходимости продолжить исследования обнаруженного противоречия. Анализируя представленные в статье результаты, можно предположить, что несоответствие размеров и составов образцов, исследованных разными методами, явилось причиной расхождения кристаллографических результатов с мессбауэровскими данными.

Учитывая разнообразие данных по химическому составу арсенопирита, характеризующихся отклонениями от стехиометрии, и принимая в расчет недостаточную кристаллографическую изученность нестехиометричных образцов минерала мы предприняли параллельное рентгеноспектральное, рентгеноструктурное и ЯГР-исследование арсенопирита на природных поликристаллических образцах. Одной из целей было выяснение возможности гармонизации химического состава, мессбауэровских и рентгеноструктурных данных. Планировалось изучить усложнение кристаллической структуры природных образцов арсенопирита. Предполагалось выяснить возможность характеризации природных образцов арсенопирита упомянутыми методами анализа для использования этих данных в прикладной минералогии. Проанализированные пробы отличаются друг от друга по составу и кристаллографическим параметрам. Все виды измерений выполнены на одних и тех же образцах, что гарантирует соответствие данных.

\section{Экспериментальная часть}

Отоор материала для исследования. Зерна арсенопирита выделены из штуфов руд путем их измельчения в металлической ступе до фракции $-1+0,5$ мм и дальнейшем обогащении водно-гравитационным методом. Мономинеральность гравиоконцентрата контролировалась под бинокулярной лупой и после визуальной очистки составила не менее 97 \%. 
Элементный химический анализ. Определение химического состава минерала выполнено методом EPMA на растровом электронном микроскопе VEGA II LMU с интегрированной системой рентгеновского энергодисперсионного микроанализатора OXFORD INCA ENERGY 350, проведено в ЦКП «Аналитический центр геохимии природных систем» Томского государственного университета. Рентгеноспектральный микроанализ осуществлен Е.В. Корбовяком.

Рентгеновское дифракционное исследование. Для подготовки образца для съемки исходный мелкокристаллический серый арсенопирит истирался в агатовой ступке до тонкого порошка и наносился в один слой на «неотражающую» кювету (монокристалл кремния, срезанный по плоскостям (910)), слегка смазанную вазелином. Дифрактограммы сняты с использованием $\mathrm{CuK \alpha} \alpha$-излучения на поликристальном дифрактометре X'Pert PRO (PANalytical) с детектором PIXcel, снабженным графитовым монохроматором. Кювета с образцом устанавливалась в стандартное положение. Съемка проводилась на отражение в геометрии $(\Theta-\Theta)$ с вращением образца со скоростью $360^{\circ}$ с. Диапазон съемки: от 5 до $101^{\circ}$ по шкале $2 \theta$, с шагом $0,026^{\circ}, \Delta \mathrm{t}-50 \mathrm{c}$.

Уточнение структуры проводилось методом полнопрофильного анализа (методом Ритвельда) с использованием программы FullProf [8]. В процессе уточнения на координаты атомов накладывались жесткие и мягкие ограничения с помощью весовых коэффициентов с учетом среднестатистических значений расстояний и углов $[9,10]$. Оптимизация структуры осуществлялась путем постепенного снятия этих ограничений при параллельном уточнении фоновых и профильных параметров. Тепловые параметры атомов первоначально уточнялись в изотропном приближении, а на последнем этапе - в анизотропном. Координаты атомов для исходной модели были взяты из [7]. По мере уточнения в модель добавлялись дополнительные атомы. Расчет областей с размытой электронной плотностью выполнялся в соответствии с методикой, описанной в работе [11].

ЯГР-спектроскопия. Мессбауэровские измерения проведены на спектрометре МС-1104Ем

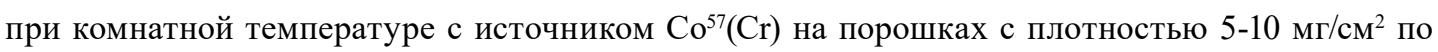
естественному содержанию железа. Расшифровка спектров проведена в два этапа. На первом этапе построена кривая распределения вероятности квадрупольных дублетов в экспериментальных спектрах P(QS) (рис. 1b). На втором - на основе данных, извлеченных из распределений $\mathrm{P}(\mathrm{QS})$, были построены модельные спектры, которые подгонялись к экспериментальным при варьировании всего набора сверхтонких параметров. Уточнению подвергались параметры всех неэквивалентных позиций железа.

\section{Результаты и обсуждение}

В анализ состояния кристаллической структуры арсенопирита было вовлечено три образца. Концентрации главных минералообразующих элементов в арсенопирите определены локальным рентгеноспектральным методом в зернах ( $\mathrm{n}$ - количество определений), выбранных из объема каждой пробы - 4x4x4 см (табл. 1).

Образцы минерала характеризуются отличием по химическому составу: I - наиболее стехиометричный, II - с дефицитом железа и избытком серы, III - с дефицитом железа и избытком мышьяка.

$$
-581-
$$


Таблица 1. Химический состав арсенопиритов

\begin{tabular}{|c|c|c|c|c|}
\hline \multicolumn{3}{|c|}{ мac. $\%$} & \multirow{2}{*}{$(\mathrm{S}+\mathrm{As}) / \mathrm{Fe}$} & \multirow{2}{*}{ S/As } \\
\hline $\mathrm{Fe}$ & As & $\mathrm{S}$ & & \\
\hline \multicolumn{5}{|c|}{ Обр. I - месторождение Олимпиада (n=22) } \\
\hline$\frac{32,79-34,74}{33,88(0,44)}$ & $\frac{45,89-47,17}{46,43(0,32)}$ & $\frac{19,15-20,05}{19,69(0,22)}$ & $\frac{1,949-2,137}{2,035(0,041)}$ & $\frac{0,971-1,012}{0,991(0,011)}$ \\
\hline \multicolumn{5}{|c|}{ Обр. II - месторождение Олимпиада (n=34) } \\
\hline$\frac{33,17-34,98}{34,03(0,46)}$ & $\frac{42,63-46,15}{44,73(0,86)}$ & $\frac{20,14-23,02}{21,24(0,73)}$ & $\frac{1,965-2,158}{2,067(0,043)}$ & $\frac{1,025-1,262}{1,110(0,058)}$ \\
\hline \multicolumn{5}{|c|}{ Обр. III - месторождение Благодатное (n=17) } \\
\hline$\frac{32,71-33,14}{32,92(0,12)}$ & $\frac{48,50-49,79}{49,10(0,33)}$ & $\frac{17,50-18,45}{17,98(0,24)}$ & $\frac{2,052-2,076}{2,063(0,007)}$ & $\frac{0,821-0,889}{0,856(0,017)}$ \\
\hline
\end{tabular}

Примечание: в числителе указан размах концентраций, в знаменателе - среднее значение, в скобках - стандартное отклонение; $\mathrm{n}$ - количество определений.

Полученные мессбауэровские спектры представляют собой квадрупольные дублеты поглощения (рис. 1a), характерные для низкоспинового состояния железа $\mathrm{Fe}(2+)$. Линии поглощения имеют асимметричную форму. Кривые распределения вероятности квадрупольных дублетов, представленные на рис. 16, имеют по 3-4 пика сложной формы. Наличие отдельных и сложных пиков на распределении $\mathrm{P}(\mathrm{QS})$ указывает на возможные неэквивалентные состояния железа. Результаты расшифровки мессбауэровских спектров без учета сложной формы основных пиков на распределении $\mathrm{P}(\mathrm{QS})$ приведены в табл. 2. Под термином «тип координации» здесь условно понимается состояние атома железа, близкое к его состоянию в одной из известных фаз. Например, «тип координации» $\mathrm{FeS}_{2}$ означает, что координационный октаэдр вокруг катиона железа формируют преимущественно анионы серы, как это происходит в пирите. В фазе $\mathrm{FeAs}_{2}$ ближайшим лигандным окружением выступают преимущественно атомы мышьяка. B FeAsS координационный октаэдр в равной мере заселен серой и мышьяком. Мессбауэровские параметры выделенных фаз близки к параметрам пирита, арсенопирита и лелингита [12]. В образцах I и II обнаруживается малое (на уровне ошибки) содержание атомов $\mathrm{Fe}(+2)$ в высокоспиновом состоянии с характерной величиной химического сдвига IS 0.6 мм/с. Это железо занимает позиции с высокой локальной симметрией. Остальное железо находится в низкоспиновом состоянии $\mathrm{Fe}(+2)$ [14].

На рис. $1 b$ видно, что пики распределения $\mathrm{P}(\mathrm{QS})$ имеют сложную форму, что свидетельствует о расщеплении основных позиций атома железа на менее различимые неэквивалентные позиции. Расшифровка спектров с допуском полного диапазона лигандного замещения серы на мышьяк приводит к результату, представленному в табл. 3. В последнем столбце здесь в фигурных скобках указан лигандный состав предполагаемых координационных октаэдров вокруг атома железа.

В соответствии с данными ЯГР-спектроскопии образец I наиболее близок к стехиометричному арсенопириту. Доли состояний железа с однолигандным окружением $\{6 \mathrm{~S}\}$ и $\{6 \mathrm{As}\}$ примерно равны и в сумме составляют около $10 \%$. На координационные полиэдры с эквивалентным содержанием серы и мышьяка приходится 90 \%. Однако из мессбауэровских дан- 


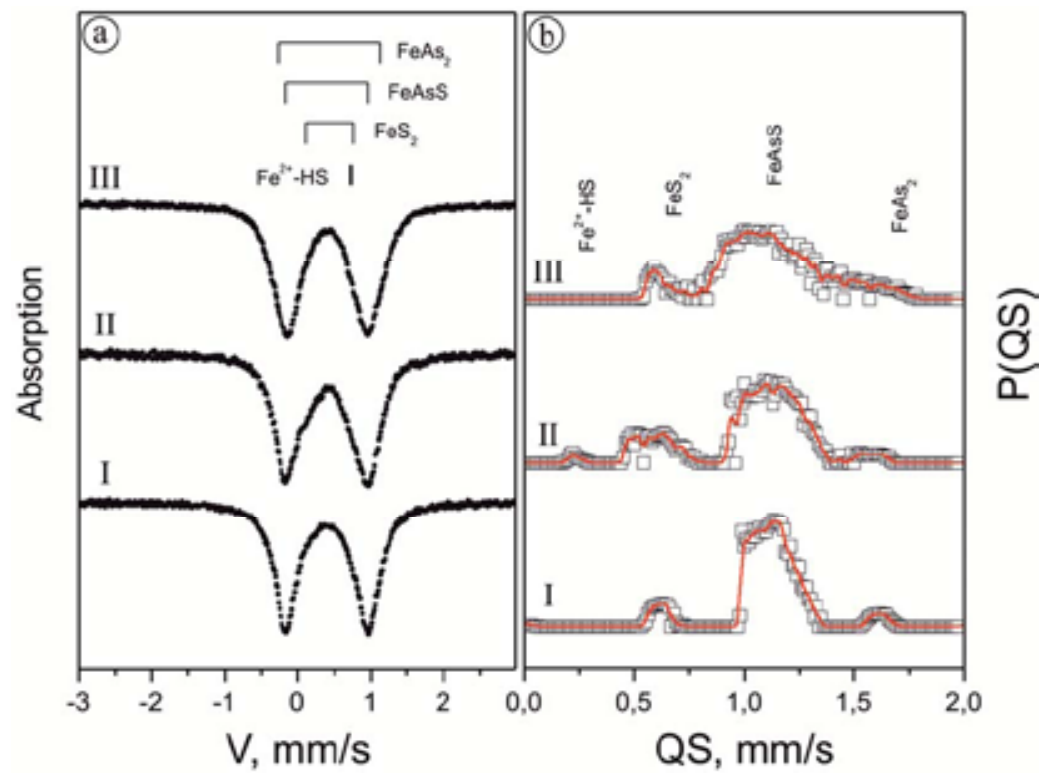

Рис. 1. a - мессбауэровские спектры образцов FeAsS; b - распределение вероятности квадрупольных расщеплений в них, красные линии здесь в усреднение по трем точкам

Таблица 2. Распределение по типу координации и мессбауэровские параметры железа в образцах арсенопирита на основе основных пиков в распределении $\mathrm{P}(\mathrm{QS})$

\begin{tabular}{|c|c|c|c|c|c|}
\hline Образец & $\begin{array}{c}\text { IS }^{(1)}, \mathrm{Mm} / \mathrm{c} \\
\quad \pm 0.005\end{array}$ & $\begin{array}{c}\mathrm{QS}^{(2)}, \mathrm{MM} / \mathrm{c} \\
\quad \pm 0.02\end{array}$ & $\begin{array}{c}\mathrm{W}^{(3)}, \mathrm{Mm} / \mathrm{c} \\
\quad \pm 0.02\end{array}$ & $\begin{array}{l}\mathrm{A}^{(4)} \\
\pm 0.03\end{array}$ & $\begin{array}{c}\text { Тип } \\
\text { координации }\end{array}$ \\
\hline \multirow{4}{*}{ I } & 0.576 & 0 & 0.25 & 0.02 & $\mathrm{Fe}^{2+}-\mathrm{BC}$ \\
\hline & 0.308 & 0.56 & 0.17 & 0.02 & $\mathrm{FeS}_{2}$ \\
\hline & 0.248 & 1.13 & 0.36 & 0.95 & FeAsS \\
\hline & 0.331 & 1.40 & 0.13 & 0.01 & $\mathrm{FeAs}_{2}$ \\
\hline \multirow{4}{*}{ II } & 0.667 & 0.05 & 0.18 & 0.02 & $\mathrm{Fe}^{2+}-\mathrm{BC}$ \\
\hline & 0.269 & 0.58 & 0.35 & 0.19 & $\mathrm{FeS}_{2}$ \\
\hline & 0.250 & 1.12 & 0.35 & 0.73 & FeAsS \\
\hline & 0.281 & 1.45 & 0.26 & 0.06 & $\mathrm{FeAs}_{2}$ \\
\hline \multirow{3}{*}{ III } & 0.246 & 0.76 & 0.32 & 0.21 & $\mathrm{FeS}_{2}$ \\
\hline & 0.251 & 1.10 & 0.32 & 0.56 & FeAsS \\
\hline & 0.261 & 1.46 & 0.34 & 0.23 & $\mathrm{FeAs}_{2}$ \\
\hline
\end{tabular}

(1) IS - изомерный химический сдвиг относительно $\alpha-\mathrm{Fe},{ }^{(2)} \mathrm{QS}-$ квадрупольное расщепление, ${ }^{(3)} \mathrm{W}-$ ширина линии поглощения, ${ }^{(4)} \mathrm{A}$ - долевая заселенность позиции.

ных следует, что состояния с эквивалентным содержанием серы и мышьяка дополнительно расщепляются на две различимые конфигурации этой позиции железа. Следует отметить, что геометрия октаэдра также допускает лишь два отличающихся способа размещения трех атомов серы и трех мышьяка по своим вершинам. Одна октаэдрическая конфигурация построена на противоположных треугольниках $\mathrm{S}_{3}$ и $\mathrm{As}_{3}$, а другая - на треугольниках $\mathrm{S}_{2} \mathrm{As}$ и

$$
-583-
$$


Таблица 3. Распределение по типу координации и мессбауэровские параметры железа в образцах арсенопирита, полученные с учетом расширенного диапазона лигандного замещения

\begin{tabular}{|c|c|c|c|c|c|}
\hline Образец & $\begin{array}{l}\text { IS, } \mathrm{MM} / \mathrm{c} \\
\pm 0.005\end{array}$ & $\begin{array}{l}\text { QS, мм/с } \\
\quad \pm 0.02\end{array}$ & $\begin{array}{c}\mathrm{W}, \mathrm{Mm} / \mathrm{c} \\
\pm 0.02\end{array}$ & $\begin{array}{c}\mathrm{A}, \\
\pm 0.03\end{array}$ & $\begin{array}{c}\text { Координационное } \\
\text { окружение }\end{array}$ \\
\hline \multirow{5}{*}{ I } & 0.586 & 0 & 0.16 & 0.02 & $\mathrm{Fe}^{2+}-\mathrm{BC}\{6 \mathrm{~S}\}$ \\
\hline & 0.388 & 0.73 & 0.17 & 0.02 & $\{6 \mathrm{~S}\}$ \\
\hline & 0.220 & 1.09 & 0.45 & 0.45 & $\{3 \mathrm{~S} 3 \mathrm{As}\}$ \\
\hline & 0.247 & 1.15 & 0.28 & 0.45 & $\{3 \mathrm{~S} 3 \mathrm{As}\}$ \\
\hline & 0.389 & 1.20 & 0.27 & 0.07 & $\{6 \mathrm{As}\}$ \\
\hline \multirow{7}{*}{ II } & 0.624 & 0.07 & 0.19 & 0.01 & $\mathrm{Fe}^{2+}-\mathrm{BC}\{6 \mathrm{~S}\}$ \\
\hline & 0.297 & 0.58 & 0.38 & 0.24 & $\{5 \mathrm{~S} 1 \mathrm{As}\}$ \\
\hline & 0.198 & 0.53 & 0.13 & 0.02 & $\{6 \mathrm{~S}\}$ \\
\hline & 0.329 & 1.04 & 0.13 & 0.05 & $\{2 \mathrm{~S} 4 \mathrm{As}\}$ \\
\hline & 0.230 & 1.08 & 0.28 & 0.42 & $\{3 \mathrm{~S} 3 \mathrm{As}\}$ \\
\hline & 0.269 & 1.31 & 0.27 & 0.19 & $\{3 \mathrm{~S} 3 \mathrm{As}\}$ \\
\hline & 0.264 & 1.58 & 0.32 & 0.07 & $\{6 \mathrm{As}\}$ \\
\hline \multirow{7}{*}{ III } & 0.318 & 0.73 & 0.38 & 0.15 & $\{6 \mathrm{~S}\}$ \\
\hline & 0.208 & 0.77 & 0.25 & 0.12 & $\{3 \mathrm{~S} 3 \mathrm{As}\}$ \\
\hline & 0.211 & 1.06 & 0.23 & 0.16 & $\{3 \mathrm{~S} 3 \mathrm{As}\}$ \\
\hline & 0.293 & 1.10 & 0.24 & 0.23 & $\{2 \mathrm{~S} 4 \mathrm{As}\}$ \\
\hline & 0.180 & 1.28 & 0.29 & 0.12 & $\{3 \mathrm{~S} 3 \mathrm{As}\}$ \\
\hline & 0.290 & 1.38 & 0.21 & 0.12 & $\{1 \mathrm{~S} 5 \mathrm{As}\}$ \\
\hline & 0.272 & 1.69 & 0.29 & 0.09 & $\{6 \mathrm{As}\}$ \\
\hline
\end{tabular}

(1) IS - изомерный химический сдвиг относительно $\alpha-\mathrm{Fe},{ }^{(2)} \mathrm{QS}-$ квадрупольное расщепление, ${ }^{(3)} \mathrm{W}-$ ширина линии поглощения, ${ }^{(4)} \mathrm{A}$ - долевая заселенность позиции.

$\mathrm{SAs}_{2}$. Однако во втором случае размещение лигандов конфликтует с симметрией арсенопирита.

Судя по распределению $\mathrm{P}(\mathrm{QS})$ (рис. 1б) степень разупорядочения координационного окружения железа возрастает в ряду I, II, III. Основные компоненты распределения превращаются в непрерывные области с большим числом компонент. В целом же тип распределения с наличием трех областей: центральной и двух боковых (с избытком серы или мышьяка в координационной сфере), сохраняется. На конфигурации с балансом серы и мышьяка приходится около половины октаэдров. Распределение площади под пиками на кривой $\mathrm{P}(\mathrm{QS})$ для образца II явно указывает на смещение стехиометрии в сторону избытка серы. Для III можно отметить небольшое преобладание координационных форм с избытком мышьяка. Между тем следует иметь в виду, что на тонкую структуру распределения может оказывать влияние не только лигандное окружение конкретного атома железа, но и распределение на соседнем атоме, поскольку соседние октаэдры имеют общие ребра и вершины.

Таким образом, ЯГР-спектроскопия фиксирует заметное разупорядочение в координационном полиэдре атомов железа, даже в образцах, близких к стехиометрии. Разупорядочение усиливается вследствие преобладания в составе образца серы или мышьяка. 
Существование кристаллографических различий образцов может быть продемонстрировано на фрагментах рентгенограмм (рис. 2), на которых имеются небольшие смещения линий, изменение их интенсивности и полуширины. Наблюдаемые изменения не следствие каких-то усреднений по составу, так как линии имеют несовпадающее положение и интенсивность. Поскольку образцы при отборе не подвергались значительному термическому воздействию, присутствующие различия являются следствием условий образования минерала или последующей эволюции. Как подтвердили расчеты, происходящие изменения еще не изменяют типа структуры, сохраняя ее симметрию и подобие решеток. Приведенные в табл. 4 параметры решетки получены в результате подгонки по профилю рентгенограммы без учета кристаллической структуры (подгонка по ЛеБейлу [13]). Можно видеть, что диапазон изменения параметров решетки не превышает $0.03 \AA$, что примерно на порядок выше, чем погрешности их определения.

Кристаллическая структура арсенопирита представлена на рис. $3 a, b$. Структурная единица - искаженный октаэдр $\left[\mathrm{FeS}_{3} \mathrm{As}_{3}\right]$, где железо является центральным атомом. В идеальном варианте атомы серы образуют одну треугольную грань октаэдра, а мышьяка - противоположную. Атом железа слегка сдвинут к сульфидному треугольнику. Каждый атом халькогена связан с тремя атомами железа, т.е. выступает вершиной трех октаэдров. Анализируя укладку октаэдров в кристаллической структуре арсенопирита, можно указать на образование лент вдоль направления [101]. В лентах октаэдры соединяются между собой по ребрам (рис. 2б). При этом возникают короткие расстояния $\mathrm{Fe}-\mathrm{Fe} \sim 2.734 \AA$ [7] в случае, когда ребро состоит из двух атомов серы. Когда ребро образуют два атома мышьяка, расстояние Fe...Fе достигает $3.741 \AA$. Нарушение в лентах регулярного чередования ребер (As...As) и (S...S), по-видимому, наиболее вероятная причина ошибок, которые сопровождаются двойникованием вдоль направления [101] в кристаллах арсенопирита $[4,5,7]$. Параллельные ленты на одном уровне по оси (в) не связаны между собой. Связь осуществляется за счет выше- и нижележащих лент (рис. $3 a$ ). При

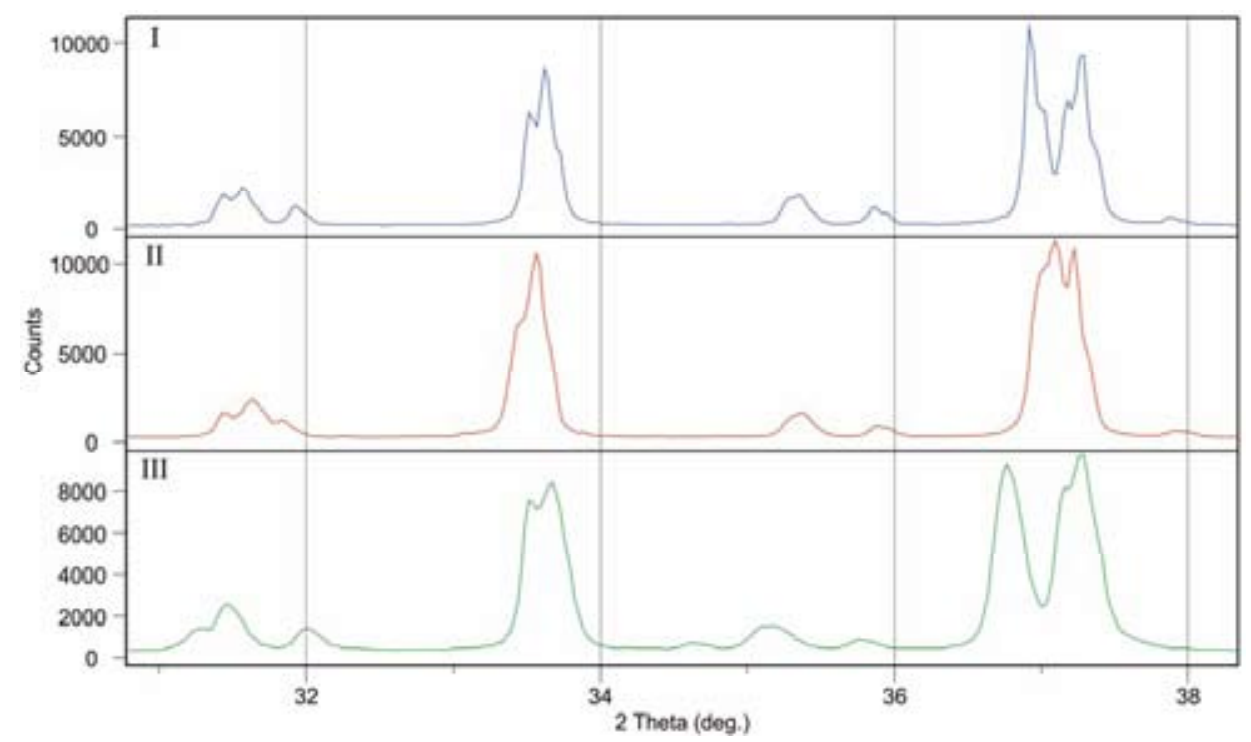

Рис. 2. Фрагменты рентгенограмм исследованных образцов с наиболее интенсивными линиями. Несовпадающее положение линий и различие в интенсивностях указывают на различие в структуре 
Таблица 4. Кристаллические данные и условия съемки для исследованных образцов арсенопирита

\begin{tabular}{|c|c|c|c|}
\hline Химическая формулаа & $\begin{array}{c}\mathrm{Fe}\left(\mathrm{As}_{0.93} \mathrm{~S}_{0.07}\right)\left(\mathrm{S}_{0.93} \mathrm{As}_{0.07}\right) \\
\text { (I) }\end{array}$ & $\begin{array}{c}\mathrm{Fe}\left(\mathrm{As}_{0.80} \mathrm{~S}_{0.20}\right)\left(\mathrm{S}_{0.92} \mathrm{As}_{0.08}\right) \\
\text { (II) }\end{array}$ & $\begin{array}{c}\mathrm{Fe}\left(\mathrm{As}_{0.84} \mathrm{~S}_{0.16}\right)\left(\mathrm{S}_{0.78} \mathrm{As}_{0.22}\right) \\
\text { (III) }\end{array}$ \\
\hline Молекуляр. вес & 162.84 & 157.68 & 165.40 \\
\hline Пр. гр. симметрии & $\mathrm{P} 2{ }_{1} / \mathrm{c}$ & $\mathrm{P} 2{ }_{1} / \mathrm{c}$ & $\mathrm{P} 2{ }_{1} / \mathrm{c}$ \\
\hline$A, \dot{A}$ & $5.7416(5)$ & $5.7361(5)$ & $5.7583(5)$ \\
\hline$B, \dot{A}$ & $5.6772(4)$ & $5.6624(5)$ & $5.6925(5)$ \\
\hline$C, \dot{A}$ & $5.7615(5)$ & $5.7568(5)$ & $5.7835(5)$ \\
\hline $\mathrm{A},\left({ }^{\circ}\right)$ & 90 & 90 & 90 \\
\hline $\mathrm{B},\left({ }^{\circ}\right)$ & $111.618(4)$ & $111.354(5)$ & $112.250(4)$ \\
\hline$\Gamma,\left(^{\circ}\right)$ & 90 & 90 & 90 \\
\hline$V_{\text {unit cell, }}, A^{3}$ & $174.59(2)$ & $174.14(3)$ & $175.46(2)$ \\
\hline$Z$ & 4 & 4 & 4 \\
\hline$V / Z, A^{3}$ & 43.65 & 43.53 & 43.89 \\
\hline$\rho_{\text {calc. }}, \mathrm{g} / \mathrm{cm}^{3}$ & 6.195 & 6.015 & 6.261 \\
\hline $\mathrm{M}, \mathrm{mm}^{-1}$ & 159.48 & 162.51 & 158.03 \\
\hline$T, K$ & 295 & 295 & 295 \\
\hline Дифрактометр & $\mathrm{X}^{\prime}$ Pert PRO & $\mathrm{X}^{\prime}$ Pert PRO & $\mathrm{X}^{\prime}$ Pert PRO \\
\hline Излучение & $\mathrm{Cu} \mathrm{K} \alpha$ & $\mathrm{Cu} \mathrm{K \alpha}$ & $\mathrm{Cu} \mathrm{K} \alpha$ \\
\hline $\begin{array}{l}\Lambda K \alpha 1, \dot{A} \\
\Lambda K \alpha 2, \AA\end{array}$ & $\begin{array}{l}1.54056 \\
1.54439\end{array}$ & $\begin{array}{l}1.54056 \\
1.54439\end{array}$ & $\begin{array}{l}1.54056 \\
1.54439\end{array}$ \\
\hline Область съемки, $2 \theta\left(^{\circ}\right)$ & $3.0-101$ & $3.0-101$ & $3.0-101$ \\
\hline Кол. точек & 3767 & 3767 & 3767 \\
\hline Кол. рефлексов s & 245 & 244 & 245 \\
\hline$R_{p}, \%$ & 6.33 & 8.10 & 8.03 \\
\hline$R_{w p}, \%$ & 8.16 & 10.40 & 10.60 \\
\hline$R_{e x p}, \%$ & 5.58 & 5.51 & 4.64 \\
\hline$S=R_{w p} / R_{e x p}$ & 1.46 & 1.91 & 2.28 \\
\hline
\end{tabular}

(a)

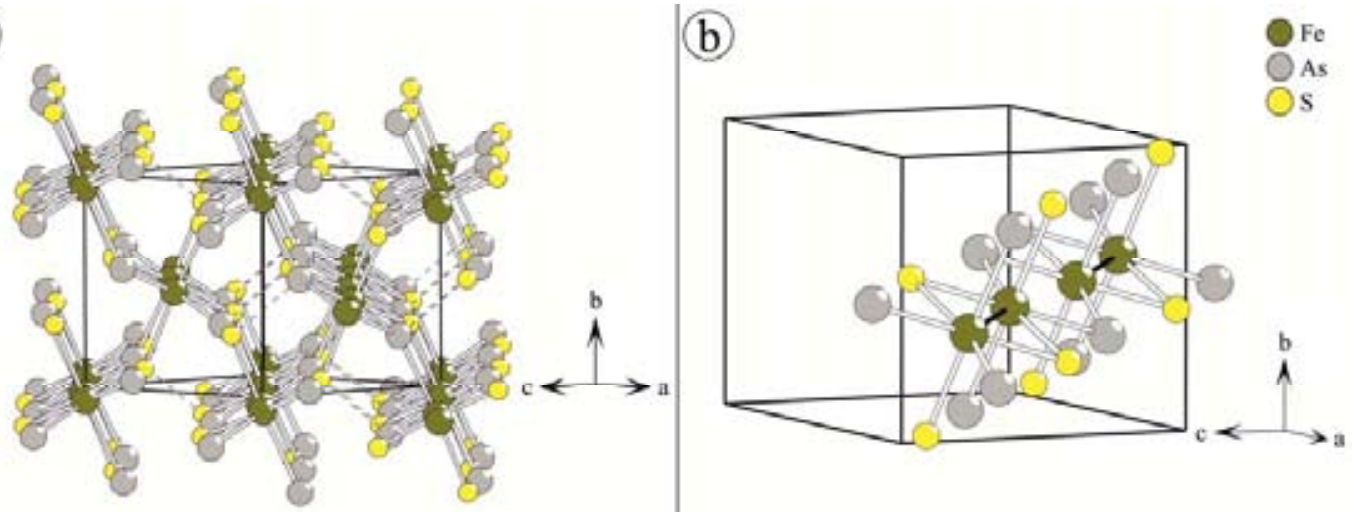

Рис. 3. а - кристаллическая структура арсенопирита FeAsS; b - чередование октаэдров $\mathrm{FeAs}_{3 / 3} \mathrm{~S}_{3 / 3}$ в лентах с образованием коротких и длинных контактов (Fe...Fe) 
таком расположении главных элементов, абстрагируясь от различия атомов в вершинах октаэдров, в арсенопирите можно обнаружить подобие структуре рутила $\left(\mathrm{TiO}_{2}\right)$.

Анализируя структуру арсенопирита, можно усмотреть искаженную плотную шаровую укладку из атомов серы и мышьяка, слои которой параллельны плоскостям с индексами (101), располагающимся вертикально и перпендикулярно к плоскости рис. $3 a$. Половина октаэдрических пустот занята атомами железа. Тетраэдрические пустоты остаются незаполненными. Смешение атомов мышьяка и серы придает пустотам более симметричное строение. С учетом этих особенностей усматривается два механизма изменения идеальной структуры арсенопирита при формировании конкретных пород. Во-первых, возможно дополнительное размещение или разупорядочение атомов металла по незанятым октаэдрическим позициям. При этом допускается изменение соотношения $\mathrm{Fe}(\mathrm{As}+\mathrm{S})$ и понижение симметрии решетки [4]. Во-вторых, высокую вероятность имеет разупорядочение серы и мышьяка по позициям неметалла. Разупорядочение с возможным изменением соотношения (As:S) ранее рассматривалось в литературе $[4,5]$, однако диспропорция в размерах атомов As и S не учитывалась. Представляется, что в реальной структуре замещение $\mathrm{As}$ на $\mathrm{S}$ должно сопровождаться небольшими изменениями в атомных позициях.

Уточнение кристаллической структуры реальных образцов арсенопирита проводилось в рамках вышеупомянутых гипотез. Основываясь на химическом составе исследуемых образцов и ограниченных интервалах изменения объема элементарной ячейки (табл. 4), мы также приняли дополнительное предположение о низком уровне вакансий в атомных позициях (не более 5 \%), что позволяет считать их практически заполненными, а соотношение $\mathrm{Fe}(\mathrm{As}+\mathrm{S})-$ близким к единице.

Исследуемые образцы имеют природное происхождение. При отборе не удалось обеспечить их полного однофазного состояния. В каждом образце присутствует небольшое количество (до 2 \%) кварца, в единичных микронных включениях имеются слюды, кальцит, полевой шпат, хлорит, сульфиды и золото. Других фаз, включая $\mathrm{FeS}_{2}$ и $\mathrm{FeAs}_{2}$, рентгенографически обнаружено не было. Уточнение структуры проводилось с учетом присутствия второй фазы. Результаты уточнения кристаллических структур собраны в табл. 4.

Образец I соответствует стехиометрическому составу. Наиболее узкие линии на рентгенограмме из трех рассматриваемых образцов свидетельствуют о более крупных кристаллитах и, по-видимому, о более равновесных условиях образования. Соответствие экспериментальной и рассчитанной рентгенограмм представлено на рис. 4a. При уточнении учитывалось наличие небольшой текстуры в направлении [101]. Для исходной модели использованы координаты из работы [7]. При уточнении структуры атомы испытывают лишь небольшой сдвиг, изменяя отдельные межатомные расстояния не более $0.02 \AA$. Заполняемость позиций мышьяка уменьшается, а серы увеличивается в пределах 5 \% (ат.). Эти изменения были интерпретированы согласно принятым гипотезам как замещение мышьяка на серу и серы на мышьяк. При небольшом уровне разупорядочения атомы серы помещались в точные позиции мышьяка, а атомы мышьяка - в позиции серы аналогично тому, как это учтено в [5]. Суммарное заполнение позиций удерживалось равным 1. Следует отметить, что обсуждаемое разупорядочение в локальном плане нарушает симметрию Р2/ $/$. Конечный баланс по составу фазы указывает на то, что разупорядочение не изменяет стехиометрии арсенопирита. Количество перемещенных атомов

$$
-587-
$$



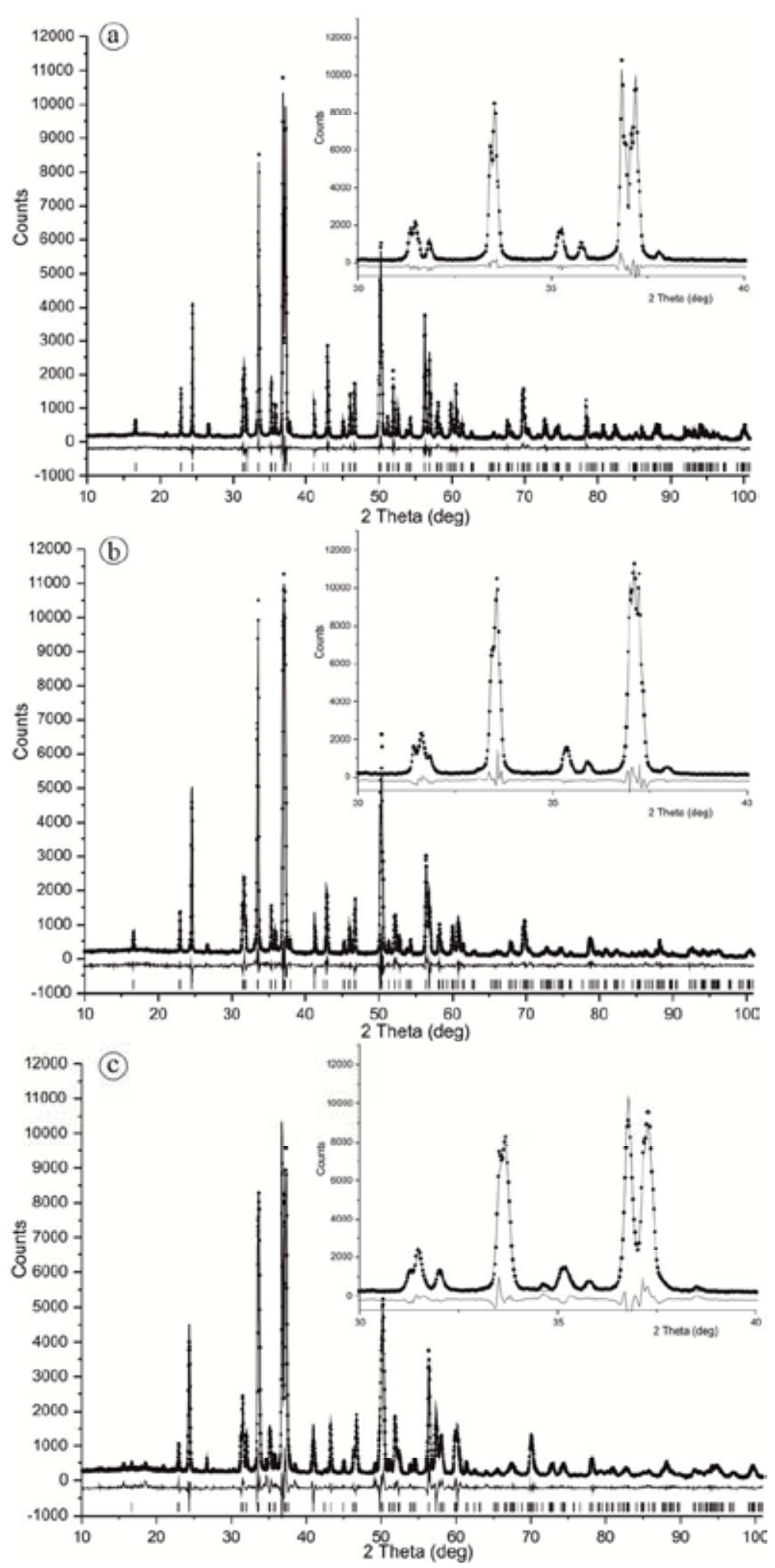

Рис. 4. Рентгенограммы исследованных образцов арсенопирита (экспериментальная - точки, рассчитанная - сплошная линия, разностная - сплошная линия в нижней части, штрих - диаграмма в нижней части). Во вставке-область рентгенограммы в увеличенном масштабе, содержащая максимальные по интенсивности линии. a - I; b - II; c - III 
мышьяка и серы составляет примерно около 7 \% (отн., ат), что соответствует данным ЯГР. Проверка гипотезы о дополнительных позициях атомов железа не позволила улучшить соответствие расчетной и экспериментальных рентгенограмм. Конечная кристаллографическая формула, отражающая изоморфное замещение атомов, может быть записана как $\mathrm{Fe}\left(\mathrm{As}_{0.93} \mathrm{~S}_{0.07}\right)$ $\left(\mathrm{S}_{0.93} \mathrm{As}_{0.07}\right)$. С точки зрения химического баланса состав соответствует стехиометрии.

Первоначальное уточнение кристаллической структуры образца (II) в рамках структурной модели [7] имело ограниченный успех $\left(\mathrm{R}_{\mathrm{pw}} \sim 13 \%\right)$. При уточнении были получены указания на большие изменения в заполнении отдельных позиций и изменения стехиометрии фазы. Значительное отклонение от стехиометрии, заметное уменьшение размеров кристаллитов указывали на определенные различия в условиях образования вещества. Эти обстоятельства явились основанием для усложнения модели. Введение дополнительных позиций для атомов железа не привело к улучшению результата. Далее было принято во внимание различие межатомных расстояний Fe-S и Fe-As, равных 2.23 и 2.40 А̊ соответственно (табл. 5). Из-за значительной их разницы при замещении атома серы на атом мышьяка последний не может занять точную позицию атома серы и наоборот. Моделирование эффекта изменения рентгенограммы при замещении было выполнено снятием ограничения при уточнении на пространственные координаты замещающего атома. Результат уточнения продемонстрирован на рис. 5б. Координационное окружение атома железа дополнилось «теневым» полиэдром, учитывающим размытие позиций серы и мышьяка. Межатомные расстояния до основных атомов координационной сферы

Таблица 5. Основные межатомные расстояния в структурах уточняемых образцов

\begin{tabular}{|c|c|c|c|c|}
\hline $\mathbf{d}(\mathbf{A}-\mathbf{B}), \boldsymbol{A}^{\prime}$ & $(\mathbf{I})$ & $(\mathbf{I I})$ & (III) & [7] \\
\hline $\mathrm{Fe} 1-\mathrm{As}^{\mathrm{i}}$ & $2.404(2)$ & $2.349(2)$ & $2.375(4)$ & $2.3702(6)$ \\
\hline $\mathrm{Fe} 1-\mathrm{As}^{\mathrm{ii}}$ & $2.413(2)$ & $2.436(2)$ & $2.402(3)$ & $2.4093(6)$ \\
\hline $\mathrm{Fe} 1-\mathrm{As}{ }^{\mathrm{iii}}$ & $2.370(2)$ & $2.349(2)$ & $2.370(3)$ & $2.4123(6)$ \\
\hline $\mathrm{Fe} 1-\mathrm{S}^{\mathrm{i}}$ & $2.228(3)$ & $2.223(2)$ & $2.242(12)$ & $2.229(1)$ \\
\hline $\mathrm{Fe} 1-\mathrm{S1}^{\mathrm{iv}}$ & $2.247(3)$ & $2.252(2)$ & $2.290(12)$ & $2.2333(9)$ \\
\hline $\mathrm{Fe} 1-\mathrm{S}^{\mathrm{v}}$ & $2.215(3)$ & $2.182(2)$ & $2.270(10)$ & $2.230(1)$ \\
\hline $\mathrm{Fe} 1-\mathrm{Fe}^{\mathrm{iv}}$ & $2.731(2)$ & $2.797(3) 1.54(1)$ & $2.786(4)$ & $2.7343(8)$ \\
\hline
\end{tabular}

Коды симметрии (i) -x, -y, 1-z; (ii) x, y, -1+z; (iii) x, 0.5-y, -0.5+z; (iv) 1-x, -y, 1-z; (v) 1-x, -0.5+y, 0.5-z.
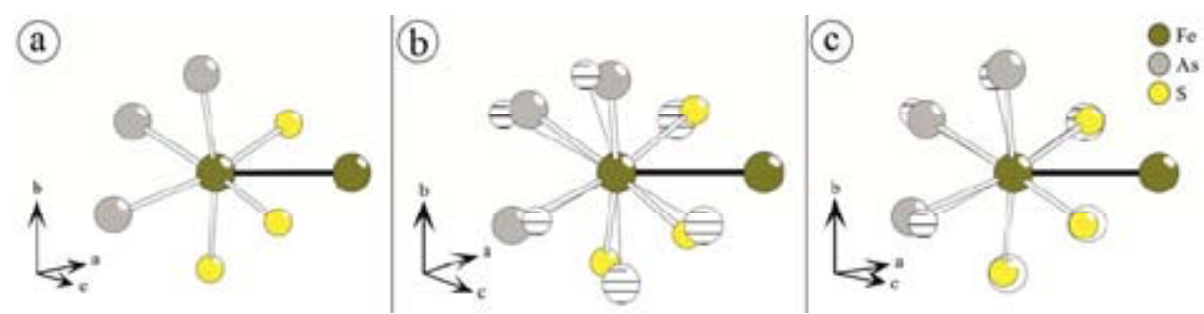

Рис. 5. Ближайшее окружение атома Fe в образце I. Изображены регулярные атомы As и S (насыщенная окраска) и дополнительные позиции (отмечены штриховкой), возникающие при частичном разупорядочении. a - образец I, b - II, c - III 
представлены в табл. 5. Можно отметить небольшое увеличение расстояний $\mathrm{Fe}-\mathrm{S}$ и, наоборот, уменьшение Fe-As по сравнению с образцом (I) и литературными данными [7].

«Теневой» полиэдр имеет слегка искаженную геометрию, которую не нужно рассматривать как реальные положения атомов. Следует иметь в виду, что группа симметрии $\mathrm{P} 2{ }_{1} / \mathrm{c}$ не позволяет разместить дополнительные атомы, равномерно удаленные от атома железа. Поэтому результат сводится не к выяснению координат дополнительных позиций, а к эффективному способу описания разориентации октаэдрического окружения атома железа.

Введение дополнительных атомов дает возможность заметно уменьшить $\mathrm{R}_{\mathrm{wp}}$ (табл. 4). Соответствие рассчитанной и экспериментальной рентгенограмм представлено на рис. 3б. Модель структуры может быть усовершенствована (усложнена) путем дальнейшего «размытия» координационного полиэдра четырьмя или большим количеством дополнительных позиций. В результате разориентация координационной сферы атома железа возрастает. В реальности в структуре одновременно присутствуют атомы железа с различным окружением, например $\left[\mathrm{FeAs}_{3} \mathrm{~S}_{3}\right],\left[\mathrm{FeAs}_{2} \mathrm{~S}_{4}\right],\left[\mathrm{FeAs}_{1} \mathrm{~S}_{5}\right],\left[\mathrm{FeAs}_{4} \mathrm{~S}_{2}\right]\left[\mathrm{FeAs}_{5} \mathrm{~S}_{1}\right]$. Естественно ожидать, что частицы с большим дисбалансом серы и мышьяка присутствуют с меньшей вероятностью. Распределение частиц с различным координационным окружением может быть смещено за счет преобладания серы или мышьяка в составе фазы. Кристаллографическая формула для образца (II), полученная в результате уточнения структуры, имеет вид $\mathrm{Fe}\left(\mathrm{As}_{0.80} \mathrm{~S}_{0.20}\right)\left(\mathrm{S}_{0.92} \mathrm{As}_{0.08}\right)$. По составу $\left(\mathrm{Fe}_{0.88} \mathrm{~S}_{1.12}\right)$ в образце имеется дефицит мышьяка, который обеспечивается преобладанием координационных форм с повышенным содержанием серы. Результат согласуется с данными ЯГР-спектроскопии, в том числе и по оценке величины дисбаланса (табл. 2, 3). Интересно отметить, что уточнение структуры данного образца выявило изменение направления преимущественной ориентации (текстуры), а именно [010], которая более свойственна кристаллам моноклинной сингонии.

В образце (III) наряду с кварцем присутствуют: кальцит, полевой шпат, хлорит, ильменит, леллингит и золото, на которые в целом приходится менее $1 \%$. Уточнение структуры образца III было выполнено по схеме, примененной для образца II. Соответствие рассчитанной и экспериментальной рентгенограмм представлено на рис. 46. Конечная кристаллографическая формула для образца III может быть записана как $\mathrm{Fe}\left(\mathrm{As}_{0.84} \mathrm{~S}_{0.16}\right)\left(\mathrm{S}_{0.78} \mathrm{As}_{0.22}\right)$. Состав соответствует стехиометрии $\mathrm{FeAs}_{1.06} \mathrm{~S}_{0.94}$ с небольшим избытком мышьяка, что коррелирует с наблюдаемым увеличением объема элементарной ячейки (табл. 4.) и данными ЯГР. Преимущественная ориентация кристаллитов связана с направлением [010]. Заметное уширение линий (рис. 2) может быть интерпретировано не только как уменьшение размеров кристаллитов, но и как следствие высокой концентрации напряжений в кристалле. Высокая концентрация точечных структурных дефектов способствует их пространственному объединению, что и проявляется как ограничение размера кристалла.

Таким образом, проведено сравнительное рентгеноструктурное и мессбауровское исследование трех образцов природного арсенопирита. Образцы в поликристаллическом состоянии были отобраны непосредственно из руд. По химическому составу один образец был близок к стехиометрии FeAsS, второй - с избытком серы и третий - с избытком мышьяка. Различие в составе проявляется на рентгенограммах образцов. Расшифровка мессбауэровских спектров показала, что железо имеет состояние окисления $\mathrm{Fe}(+2)$. В каждом образце различаются три 
группы состояний атомов железа по виду координационного окружения. Каждая из групп имеет сложный состав, из которого могут быть выделены простые состояния. Рентгеноструктурное исследование не выявило дополнительных кристаллографических позиций для атомов железа ни в одном из образцов. Катионная решетка структуры практически не изменяется, однако нельзя исключить небольшого размытия основной позиции атома железа. Происходящие изменения в основном затрагивают анионную подрешетку. Было обнаружено разупорядочение лигандного окружения железа. Замещение серы на мышьяк и наоборот сопровождается небольшим сдвигом атомной позиции из-за разницы межатомных состояний Fe-S и Fe-As. B результате образуется набор состояний атома железа, различающихся по составу координационной сферы и по пространственной конфигурации заместителей. Разупорядочение координационного окружения фиксируется ЯГР-спектроскопией.

Наблюдаемое разнообразие состояний, по-видимому, является отражением условий образования минерала, в частности температуры. Структура арсенопирита может быть устойчивой как с избытком серы, так и мышьяка, однако интервал устойчивости ограничен.

\section{Благодарности}

Работа выполнена при финансовой поддержке Министерства образования и науки РФ, программа «Организация проведения научных исследований», № 1025.

\section{Список литературы}

[1] Kretschmar U., Scott S.D. Phase relations involving arsenopyrite in the system Fe-As-S and their application. Can. Mineral. 1976. 14. 364-386.

[2] Cipriani C., Borrini D., Mazzetti G. Revisione della collezione di arsenopiriti del Museo di Mineralogia dell'Universita di Firenze. Mus. Scient. 1998. 14. 219-228.

[3] Buerger M.J. The symmetry and crystal structure of the minerals of the arsenopyrite group. Zeitschrift fur Kristallographie. 1936. 95. 83-113.

[4] Morimoto N., Clark L.A. Arsenopyrite crystalchemical relations. Am. Mineral. 1961. 46. 14481469.

[5] Fuess H., Kratz T., Topel-Schadt J., Miehe G. Crystal structure refinement and electron microscopy of arsenopyrite. Z. Kristallogr. 1987. 179. 335-346.

[6] Murzin V.V., Semenkin V.A., Sustavov S.G, Krinov D.I., Pikulev A.I., Milder O.B. Nonequivalent positions of $\mathrm{Fe}$ atoms in gold bearing arsenopyrite according to Mossbauer spectroscopy. Geokhimiya. 2003. 8. 893-901. (in Russian)

[7] Bindi L., Moelo Y., Leone P., Suchaud M. Stoichiometric arsenopyrite, FeAsS, from La Roche-Balue Quarry Loire-Atlantique, France: Crystal structure and Mossbauer study. The Canadian Mineralogist. 2012. 50. 471-479.

[8] Rodriguez-Carvajal J. Full Prof version 4.06, March 2009, ILL (unpublished).

[9] Kirik S.D. Refinement of the crystal structures along the powder pattern profile by using rigid structural constraints. Kristallographia. 1985. 30. 185-187. (in Russian)

[10] Fedorov V.E., Evstafyev V.K., Kirik S.D., Mischenko A.V. Synthesis, structure and properties of the novel niobium chalcohalides NbXY. Russian J. of Inorganic Chemistry. 1981. 26(10). 2701-2707. (in Russian)

$$
-591-
$$


[11] Kirik S.D., Dubkov A.A., Dubkova S.A., Sharonova O.M., Anshits A.G. X-ray powder.study of $\mathrm{SO}_{2}$ adsorption on type Yzeolite. Zeolites. 1992. 12. 292-298.

[12] Kjekshus A., Nicholson D.G. The Significance of pi Back-bonding in Compounds with Pyrite, Marcasite, and Arsenopyrite Type Structures. Acta Chem. Scand. 1971. 25. 866-876.

[13] LeBail A., Duroy H., Fourquet J. L. Ab-initio structure determination of LiSbWO6 by X-ray powder diffraction. Mater. Res. Bull. 1988. 23. 447-452. 